\title{
Изучение личности Гипатии в зарубежной историографии
}

\author{
Суслов Ф.А. \\ МБОУ СОШ № 35, \\ 308000 г. Белгород, ул. Преображенская, 14 \\ E-mail: fedor-suslov@mail.ru
}

\begin{abstract}
Аннотация. В статье делается анализ степени изученности личности Гипатии и основных тенденций по этой проблематике в зарубежной историографии. Образ Гипатии привлекал внимание исследователей еще начиная с XVIII в. Популярность образа связана с тем, что она являлась женщиной-ученым и главой школы в Александрии, а также с её жестоким убийством радикальными христианами из группировки парабаланов. Гипатия стала символом мученицы за язычество, а её убийство - свидетельством жестокости и нетерпимости христиан. В течение XIX и $\mathrm{XX}$ вв. тема Гипатии продолжала изучаться, привлекая внимание всех школ и направлений. Настоящий бум исследовательской активности наблюдается с 1980-90-х гг., когда появились первые специализированные монографии по Гипатии. На данный момент Гипатия является самым популярным позднеантичным философом, входя в пятерку самых популярных философов античного мира вообще, вызывая исследовательский интерес от исследователей со всей Европы, а также США, Австралии, ЮАР и Южной Кореи. Главное внимание привлекают темы её убийства, связанные с межконфессиональными отношениями в позднеантичной Александрии, её философское учение, изыскания в области точных наук, возглавляемая ею школа, а также личная и публичная жизнь, социальные связи. На данный момент наиболее острые дискуссии ведутся по роли патриарха Кирилла в её убийстве, по значению Гипатии для математики и философии, а также по направлению неоплатонизма, которому она следовала. Основной проблемой является трудность исследования творчества Гипатии в области математических наук для историковгуманитариев. Огромное внимание к Гипатии приковано со стороны феминистического движения, символом которого она является.
\end{abstract}

Ключевые слова: Гипатия, зарубежная историография, зарубежное антиковедение, поздняя античность, Александрия, св. Кирилл Александрийский.

Для цитирования: Суслов Ф.А. 2021. Изучение личности Гипатии в зарубежной историографии. Via in tempore. История. Политология, 48 (2): 299-317. DOI: 10.52575/2687-0967-2021-48-2-299-317.

\section{The study of the personality of Hypatia in foreign historiography}

\author{
Fedor A. Suslov \\ Municipal budgetary educational institution Secondary school № 35, \\ 14 Preobrazhenskaya St., Belgorod, 308000, Russia \\ E-mail: fedor-suslov@mail.ru
}

\begin{abstract}
This article analyzes the degree of study of the personality of Hypatia and the main trends on this issue in foreign historiography. The image of Hypatia has attracted the attention of researchers since the 18th century. The popularity of the image is due to the fact that she was a woman philosopher and head of the school in Alexandria, as well as her brutal murder by radical Christians from the parabolan group. Hypatia became a symbol of a martyr for paganism, and her murder is evidence of the cruelty and intolerance of Christians. During the 19th and 20th centuries, the topic of Hypatia continued to be studied, attracting the attention of all schools and trends. A real boom in research activity has been observed since the 1980s and 90s, when the first specialized monographs on Hypatia appeared. At the moment, Hypatia is the most popular late antique philosopher, one of the five most popular philosophers of the ancient world in general, arousing research interest from researchers from all over Europe, as well as the USA,
\end{abstract}


Australia, South Africa and even South Korea. The main attention is drawn to the themes of her murder associated with interfaith relations in late antique Alexandria, her philosophical teachings, research in the field of exact sciences, the school she heads, as well as personal and public life, social ties. At the moment, the most acute debates are on the role of Patriarch Kirill in her murder, on the importance of Hypatia for mathematics and philosophy, as well as on the direction of neo-Platonism, which she followed. The main problem is the difficulty of researching the work of Hypatia in the field of mathematical sciences for humanist historians who cannot fully appreciate her work. Huge attention to Hypatia is riveted on the part of the feminist movement, of which she is a symbol.

Key words: Hypatia, foreign historiography, foreign classical studies, late antiquity, Alexandria, St. Cyril of Alexandria.

For citation: Suslov F.A. 2021. The study of the personality of Hypatia in foreign historiography. Via in tempore. History and political science, 48 (2): 299-317 (in Russian). DOI: $10.52575 / 2687-0967-2021-48-2-299-317$.

\section{Введение}

В центре внимания данной работы - изучение в зарубежной историографии личности и деятельности знаменитой женщины-философа позднеантичной Александрии Гипатии, дочери математика и астронома Теона, которая была жестоко убита в 415 г. радикальной группировкой христиан-парабаланов, возглавляемой Петром Чтецом (Philostorg. HE. VIII. 9; Socr. HE. VII. 15; Damasc. fr. 43, 106; Malal. Chron. XIV. 12; Ioan. Nik. Chron. LXXXIII (LXXXIV). 87-103; Theoph. Chron. a. 5906/406; Suid. Y 166; Anthol. Gr. IX. 400).

\section{Результаты и их обсуждение}

Эта тема издавна привлекала внимание ученых-историков. Это был пример женщины, пробившейся на высокие ступени общественной лестницы в эпоху древнего мира, причем за счет своего ума и образованности. Интерес к ней возник еще в византийской исторической традиции, а через Кассиодора ее образ получил распространение также и в Западной Европе [Watts, 2017, p. 124].

Возрождение интереса к Гипатии состоялось в эпоху Просвещения, когда началось развитие идей равенства и истоки эмансипации женщин в европейском обществе. В 1720 г. ирландский философ-протестант Джон Толанд (1670-1722) [Watts, 2017, p. 135] публикует длинное эссе о Гипатии, название которого можно перевести примерно так: «Гипатия, или История самой прекрасной, самой целомудренной, самой ученой и во всех отношениях совершенной Леди; которая была разорвана на куски духовенством Александрии, чтобы удовлетворить гордость, соперничество и жестокость своего Архиепископа, обычно, но незаслуженно украшенного святого Кирилла» [Toland, 1753]. В ней он на основе византийских источников всячески восхваляет Гипатию, противопоставляя ее добродетель мерзости Кирилла Александрийского. Это произведение имело явную антиклерикальную направленность против Католической Церкви [Dzielska, 1995, p. 2]. В ответ ему выступил англичанин Т. Льюис в 1721 г. [Watts, 2017, p. 136], написавший памфлет «История Гипатии, самой бесстыдной учительницы Александрийской школы: убитая и растерзанная на куски населением в защиту святого Кирилла и александрийского духовенства. Против клеветы мистера Толанда» [Lewis, 1721]. В нем он доказывал, что Гипатия не была столь выдающаяся и образованная, как представлено в работе Толанда, а была обычной женщиной-язычницей. Её смерть использована как часть атаки на св. Кирилла со стороны еретика Сократа Схоластика и язычника Дамаския.

В 1728 г. вышла более глубокая диссертация анонимного автора с инициалами M.G. на французском языке: «Диссертация о Гипатии, где оправдывается Святой Кирилл Александрийский от обвинения в смерти этого ученого». Она была переиздана и позднее [Desmolets, 1749a]. В этой работе признавались таланты и достоинства Гипатии как учено- 
го, но на основе филологической критики опровергались обвинения Сократа Схоластика и Дамаския против Кирилла как виновника убийства. Доказывалась тенденциозность античных источников и противоречия, содержащиеся в них, а также то, что Петр Чтец, возглавлявший группу парабаланов - убийц Гипатии, действовал по собственной инициативе. В конце диссертации было приложение в виде письма некой мадемуазель Б., которая хвалила диссертацию за внимание к женщине-ученому и достижениям женщин в области наук [Desmolets, 1749b].

В 1772 г. также вышла статья Вольтера о Гипатии в «Философском словаре» [Voltaire, 1860], где он обратил внимание на упоминание в источниках, что Гипатию раздели догола, перед тем как убить. Это задало новое направление интереса к Гипатии, в частности, обращение к темам женственности, эротизма, молодости и красоты, несмотря на упоминание в источниках о весьма зрелом возрасте Гипатии [Watts, 2017, p. 139]. Тем не менее дискуссия имела выраженную религиозную направленность, а сама личность Гипатии рассматривалась как легендарная.

Аналогичные взгляды о Гипатии выражены в знаменитом труде британского историка XVIII в. Э. Гиббона. В своей «Истории упадка и гибели Римской империи» (1776-1788) он представляет Гипатию как мученицу за язычество, убитую жестокими фанатиками за свои взгляды [Gibbon, 1781, p. 82-93, 312-323; Dzielska, 1995, p. 3-4].

C XIX в. Гипатия начала занимать свою нишу в литературе и искусстве. Стало появляться множество новых исторических романов о Гипатии, она показывалась в поэтических и драматических произведениях, памятниках искусства [Watts, 2017, p. 140-141; Dzielska, 1995, p. 3-12). Это стимулировало исследовательский поиск и профессиональный исторический интерес к Гипатии.

В 1860 г. появилось глубокая статья немецкого исследователя Р. Хохе «Гипатия, дочь Теона», но она не рассматривала математические штудии Гипатии [Ноche, 1860, S. 435-474]. В 1879 г. С. Вольфом издан аннотированный справочник по первоисточникам о Гипатии [Wolf, 1879]. В 1880 г. вышла небольшая статья П. Таннери, где анализировались данные «Суды» как источник по жизни Гипатии [Tannery, 1880, p. 197-200]. В 1886 г. В. Мейер подготовил диссертацию «Гипатия Александрийская: вклад в историю неоплатонизма» [Meyer, 1886], где детально рассматривалась жизнь и философская деятельность Гипатии. В 1887 г. также вышла обширная статья Г. Бигони [Bigoni, 1886/1887], который подробно исследовал биографические вехи женщины-философа, правда, ее научным штудиям уделил весьма мало внимания [Deakin, 2007, p. 215]. Внимание Гипатии уделено и в фундаментальном 6-томном труде «История падения античного мира» немецкого историка О. Зека, выпускаемом с 1895 по 1920 гг., где он подробно исследует дату смерти ученой женщины [Seeck, 1966, p. 78-79, 404-405].

В 1-й пол. ХХ в. интерес к исследованию жизни и деятельности Гипатии продолжился, однако он не носил системного характера, каких-либо крупных трудов не появлялось, ученые ограничивались предметными статьями. В 1907 г. немецкий исследователь Р. Асмус выпустил статью, посвященную изучению Гипатии в исторической традиции и поэтической литературе [Asmus, 1907, p. 26-27]. В 1920-е гг. вышла статья А. Роме, где впервые изучались математические штудии Гипатии, в частности, её совместные с отцом комментарии к «Амальгесту» [Rome, 1926, p. 1-14]. В 1940 г. крайне информативную статью о Гипатии подготовил А. Ричесон, однако, хотя она была напечатана в математическом журнале, там было весьма мало рассуждений о математических методах Гипатии [Richeson, 1940, p. 74-82].

В 1950-60-е гг. определенный интерес проявлялся к философскому учению Гипатии и её роли в неоплатонической традиции. А. Марру изучал влияние учения Гипатии на её самого известного ученика Синесия [Marrou, 1952, p. 474-484; 1964, p. 126-150], Дж. Рист рассматривал кинические аспекты философии Гипатии [Rist, 1965]. В 1970-е гг. активнее стала затрагиваться математическая и астрономическая стороны деятельности 
Гипатии. Комментарии к Диофанту рассмотрены в статье Р. Раше [Rashed, 1974, p. 97-122; 1975, p. 3-30]. В 1975 г. вышла монография О. Нейгебауэра «История древней математической астрономии», где рассматривалась астролябия, которую использовали Теон и Гипатия в своих астрономических исследованиях [Neugebauer, 1975, p. 873]. Ранее астролябии он же посвятил отдельную большую статью [Neugebauer, 1949, p. 240-256]. Интересна статья Э. Эврара, в которой исследуется официальный статус Гипатии в школе Теона; автор приходит к выводу, что она не занимала официальной должности [Évrard, 1977, p. 69-74].

Некий бум исследований по Гипатии наблюдался в 1980-90-е гг. Именно тогда были основаны два феминистических журнала, носящих имя античного философа: в 1984 г. открыт журнал «Нураtia: Feminist Studies» в Афинах, а в 1986 г. - «Hypatia: A Journal of Feminist Philosophy» в Кембридже [Watts, 2017, p. 144]. Последний имеет свой сайт.

Также в это время появляется ряд важных публикаций. Интересна статья Роберта Пенеллы, где рассматривалась дата рождения Гипатии; автор приходит к выводу, что она родилась много ранее 370 г. [Penella, 1984, p. 126-128].

В 1987 г. был издан библиографический сборник о женщинах-математиках, где даны 43 биографии этих женщин, их достижения, список трудов и библиография, и среди них также статья И. Мюллер о Гипатии, которая кратко, но ёмко излагает все основные моменты её жизни и деятельности, в том числе в области математики [Mueller, 1987, p. 74-79].

В этом же году М. Вейз был издан первый том серии «История женщинфилософов», посвященный женщинам-философам античности с 600 г. до н. э. до 500 г. н. э. Глава 9 этого сборника посвящена Гипатии, где также излагается биография и научно-преподавательская деятельность позднеантичной ученой, а также дается большой материал по математическим работам Гипатии с обсуждением её комментариев к работам античных математиков [Waithe, 1987, p. 169-197]. Но рассмотрение этих вопросов базируется на более давних исследованиях, не учитывая новейшие работы по истории математики на тот момент [Deakin, 2007, p. 222].

В 1989 г. вышла еще одна общая работа В. Кнорра «Текстовые исследования в античной и средневековой геометрии», где 11 глава посвящена Гипатии. Там делается попытка реконструировать её собственные математические исследовании на основе анализа комментариев к «Амальгесту» Птолемея, сделанных Теоном совместно с дочерью [Knorr, 1989].

На эту работу сделал критический отклик английский исследователь Алан Кэмерон, пришедший к выводу о том, что Гипатия гораздо меньше участвовала в редактировании комментариев своего отца, чем это думал Кнорр [Cameron, 1990, p. 103-127]. А в его совместной с Дж. Лонг монографии «Варвары и политика при дворе Аркадия», построенной на основе анализа произведений Синесия, есть подраздел 2.5, посвященный Гипатии, где кратко излагается жизнь и учение учёной; в частности, делается интересный вывод о том, что философия Гипатии и её отца Теона сильно зависела от мистического неоплатонизма Ямвлиха [Cameron, Long, 1993, p. 39-62].

В 1995 г. появилась первая серьёзная монография, посвященная специально Гипатии. Её подготовила польская исследовательница М. Дзельска [Dzielska, 1995]. О важности книги говорит ее переиздание в Гарварде. Сочинение разделено на 3 главы: 1 глава «Литературная легенда о Гипатии», там исследуется образ Гипатии в исторической науке и культуре Нового и Новейшего времени; 2 глава - «Гипатия и её круг», это наиболее интересная и подробная глава в книге, в которой делается попытка реконструкции круга учеников Гипатии, прежде всего, на основе писем Синесия. Развивается интересная точка зрения, что брат одного из учеников Гипатии Геркулиана, которого звали Кир и который предположительно также проходил обучение в школе Гипатии, мог быть одним и тем же лицом, что и образованнейший префект Восточной префектуры претория и префект Константинополя 1-й пол. V в. Кир Египетский, прославившийся как поэт и философ и обви- 
ненный в язычестве при императоре Феодосии II [Dzielska, 1995, p. 31]. Если эта гипотеза верна, то она показывает глубокое влияние школы Гипатии на интеллектуальную жизнь империи. 3 глава - «Жизнь и смерть Гипатии», посвящена непосредственно биографии Гипатии, а также её научной деятельности. Автор пытается реконструировать математические и астрономические штудии Гипатии, однако делает это поверхностно [Deakin, 2007, p. 216].

Помимо этой монографии в 1990-е гг. Н. Ниетупски была подготовлена обобщающая статья о Гипатии «Гипатия: математик, астроном и философ» [Nietupski, 1993, p. 46-62], где рассмотрены астрономические достижения Гипатии, а в статье Б. Витфилда анализируются достижения в области математики [Witfield, 1995, p. 14-21]. В статье Д. Роке изучается семья Гипатии [Roques, 1995, p. 128-149]. В статье В. Бэрри рассмотрены и проанализированы обстоятельства убийства учёной [Barry, 1996, p. 55-74].

В 1997 г. вышла важная монография Кристофера Хааса «Александрия в поздней античности: топография и социальные конфликты», где затрагиваются и проблемы убийства Гипатии в контексте конфликта с патриархом Кириллом. Но внимание Хааса сосредоточенно на этнорелигиозных социальных конфликтах в городе, а не на деятельности самой Гипатии [Haas, 1997, p. 295-316].

В новом тысячелетии внимание к Гипатии со стороны исследовательского сообщества только возрастает. Многие исследователи сосредотачиваются на проблемах религиозного конфликта Гипатии с Кириллом и её убийства. Эти вопросы изучает в своей статье Пекка Хейкура, где он приходит к выводу о том, что Гипатия склонялась к грекоримскому плюрализму и не участвовала в местных религиозных культах, поэтому не была популярна у местного языческого сообщества [Heikura, 2000].

Убийство Гипатии освещено в монографии К. Крамера [Kramer, 2006], статьях Л. Карлоу [Karlow, 2005/2006, p. 2-26], А. Беленького [Belenkiy, 2010, p. 9-13]. Последний выдвинул интересную гипотезу о том, что убийство Гипатии было связано с её астрономическими наблюдениями и опровержением рассчитанной церковниками даты пасхалий.

Также стало развиваться новое направление рецепции образа Гипатии и Кирилла Александрийского в современности. В 2007 г. Жаклин де Медичи подготовила работу «Любимые и проклятые: Гипатия и Кирилл от поздней античности до современности» [Medicci, 2007]. Здесь рассматриваются основные легенды и мифы о Гипатии на протяжении истории.

Разрабатывались и другие темы. В частности, Сильвия Ронкей подготовила статью, где рассматривала Гипатию и её отношения с Синесием с точки зрения женственности и как вариант платонической любви. Гипатию и Синесия исследовательница считала ровесниками, а также отмечала высокий уровень классической «эллинской» культуры у Гипатии, что вызывало симпатии к ней со стороны нехристианской аристократии, но в то же время вызывало проблемы с официальной идеологией [Ronchey, 2005, p. 129-138]. Ранее Ронкей подготовила статью о Гипатии в сборнике «Римские женщины», посвященную интеллектуальной деятельности Гипатии как философа [Ronchey, 1999, p. 160-189].

Большое внимание уделено научно-образовательной деятельности Гипатии. В ходе раскопок в одном из регионов Александрии Ком-эль-Дикка были найдены остатки аудиторий. Это стимулировало публикационную активность. Р. Крибиоре подготовила общую статью об образовательном пространстве в поздней античности [Cribiore, 2007, p. 143-150], польский археолог Г. Майчерек показал устройство аудиторий с точки зрения археологии [Majcherek, 2007]. Джудит Маккензи подготовила фундаментальную монографию по архитектуре Александрии и Египта с 300 г. до н. э. по 700 г. н. э. [McKenzie, 2007].

В 2006 г. Эдвард Уоттс издал глубокую монографию «Город и школа в позднеантичных Афинах и Александрии», где изучает деятельность двух крупнейших образовательных центров поздней античности в IV-V вв. Научно-образовательную деятельность и убийство Гипатии Уоттс подробно рассматривает в 4-й главе своего труда, посвященной 
культурной жизни Александрии в конце IV в., в специальном подразделе «Гипатия и языческая философская культура в конце IV в.». Особенно интересны его выводы о философском учении Гипатии. В противовес Алану Кэмерону, Уоттс считает Гипатию не последовательницей неоплатонизма Ямвлиха и теургии, а наследницей очищенного от религиозных практик умопостигаемого неоплатонизма Плотина, что привлекало в её школу огромное число студентов-христиан. Школу Гипатии Уоттс считает центральной в Александрии в начале V в. [Watts, 2006, p. 187-203].

Наиболее глубокую и фундаментальную работу по Гипатии в начале XXI в. подготовил историк и математик Майкл Дикин, который впервые с профессиональных позиций комплексно проанализировал математические штудии Гипатии и рассмотрел ее достижения в качестве математика. Его работа «Гипатия Александрийская: математик и мученик» была издана в 2007 г. [Deakin, 2007]. Она состоит из Введения, 10 глав с приложениями и аннотированной библиографией. Работа обладает четкой и продуманной, очень логичной структурой. Во введении автор ставит проблему, показывает развитие образа Гипатии в культуре и его актуальность для современности. Глава 1 посвящена историческому контексту жизни Гипатии, дана краткая характеристика политического развития империи в поздней античности. Глава 2 затрагивает интеллектуальный контекст, то есть развитие математических знаний в Александрии ко времени жизни Гипатии, в частности рассматриваются те математики, которых комментировали Теон и Гипатия. Во второй части главы дан краткий обзор развития неоплатонического учения в поздней античности. В главе 3 представлен религиозный контекст, то есть внутрихристианские теологические споры в поздней античности: тринитарные, христологические и др., особенно касательно Александрии. Во второй части главы дается разбор догматики неоплатонизма, а в третьей концепция троичности Божества, характерная для христиан и неоплатоников. Глава 4 комплексно характеризует источники по Гипатии, причем помимо нарративных позднеантичных и византийских источников (церковные истории, хроники, биографические статьи «Суды», на основе которых реконструируется «Ономатолог» Гесихия Милетского и «Философская история» Дамаския и т. п.) автор затрагивает собственно математикофилософские работы, в частности математические комментарии Теона и Гипатии. Не обходит вниманием он и работы Синесия как источник по жизни и философскому учению Гипатии. Но в то же время некоторые источники автором проигнорированы, например, не упомянута «Церковная история» Филосторгия, а также некоторые данные византийской традиции [Deakin, 2007, p. 45-46]. В главе 5 обобщены сведения о жизни Гипатии, в том числе на основе данных заглавной части комментариев Теона выдвинута интересная гипотеза о том, что у Гипатии был брат Епифаний, который мог быть жрецом местного языческого культа. Отметим, что автор отказывается от спекулятивных построений о матери Гипатии, так как по ней совершенно нет данных [Deakin, 2007, p. 52-53]. Глава 6 посвящена преподавательской работе Гипатии в школе, её социальным связям и образу жизни. Автор подчеркивает, что учёная занимала высокое общественное положение, поэтому часто общалась с высшими должностными лицами города. Также представлен её предположительный уровень научных знаний, в том числе в области астрономии и математики. В главе 7 анализируется смерть Гипатии. Автор рассматривает её с точки зрения этносоциальных конфликтов и борьбы между христианами, иудеями и язычниками, следуя письменным источникам. В главе 8 делается попытка комплексной реконструкции философского учения Гипатии на основе трактатов её ученика Синесия как варианта конспекта лекций своего учителя. Наиболее интересна глава 9, посвященная математическим трактатам Гипатии. Автор в ней системно характеризует источники математических штудий Гипатии, а затем те трактаты, которые приписываются позднеантичной учёной: комментарии Теона на «Амальгест» Клавдия Птолемея, особенно на книгу III, приписываемую единоличному авторству Гипатии, а также комментарии на «Коники» Аполлония, «Арифметику» Диофанта, «Астрономический канон» Птолемея, а также работы, авторство Гипа- 
тии для которых не доказано, но могло быть. Особо рассматриваются приборы, которые использовала, а возможно, и самостоятельно разработала Гипатия: астролябия и гидроскоп. Автор дает их функциям не религиозно-мистическое, как принято у многих историков, а естественно-научное объяснение, например, рассматривает гидроскоп как ареометр - прибор для измерения плотности жидкостей, который Синесий просил для практических нужд своего лечения [Deakin, 2007, p. 104-105]. Последняя 10 глава наиболее интересна, здесь М. Дикин делает выводы о вкладе работ Гипатии в развитие математических наук. Он приходит к интересному выводу, что собственно научная деятельность Гипатии переоценена, так как никаких самостоятельных научных математических трудов за Гипатией доподлинно не известно, а лишь комментарии к другим математикам, которые нужны в образовательном процессе. Гипатия адаптировала более сложные работы применительно к уровню своих студентов. В плане философии Гипатия имела скорее эклектичные взгляды. В то же время её педагогическая деятельность была на высоком уровне, её лекции были очень популярны, а студенты её очень любили.

Интересны приложения к работе. В прил. 1 дается визуальная реконструкция приборов и геометрических фигур Гипатии и, собственно, математический разбор положений и теорем Гипатии и тех математиков, которых она комментировала. Прил. 2 содержит сведения о еще одной женщине-математике поздней античности Пандросионе, а также критический разбор её дискуссии с математиком IV в. Паппом Александрийским. Прил. 3 рассматривает легенду о св. Екатерине Александрийской, причем автор выдвигает интересную гипотезу о том, что это христианская адаптация образа Гипатии в плане жизни и мученической смерти [Deakin, 2007, p. 135-136]. В прил. 4 собраны переводы всех известных письменных источников о жизни Гипатии: словарей «Суды» (X в.) и Гесихия Милетского (VI в.), философской истории язычника Дамаския (V-VI в.), церковных историков Сократа Схоластика (IV-V вв.), Иоанна Никиусского (VII в.), писем Синесия Гипатии и друзьям о Гипатии; а также отдельно вынесены в «Разное» иные источники: заголовки с биографическими сведениями в комментариях Теона, извлечения из хроник Иоанна Малалы (VI в.) и Феофана (IX в.), а также данные из «Церковной истории» Филосторгия (IV-V вв.), которые проигнорированы в основной части. Работу Дикина можно считать если не лучшей, то одной из лучших по научной деятельности Гипатии.

В 2008 г. писательница Сэнди Донован издала научно-популярную книгу «Гипатия: математик, изобретатель и философ», адаптированную для подростков в серии «Замечательные жизни: древний мир» [Donovan, 2008]. Она содержит общие факты о жизни Гипатии. В 2010 г. вышла статья А. Бернара о Теоне и Гипатии в «Кембриджской истории философии в поздней античности», изучавшая философские взгляды обоих позднеантичных ученых [Bernard, 2010, p. 417-436].

Увеличение интереса к Гипатии в наши дни продолжается, она стала символом современного феминистического движения [Cameron, 2016, p. 185]. Это частично связано с выходом на экраны в 2009 г. фильма «Агора» испанского режиссера Алехандро Аменабара. Это историческая драма о борьбе христиан и язычников в позднеантичной Александрии, где главным действующим лицом была Гипатия [Heijden, 2016, p. 111]. Согласно статистике поисковых запросов Google на июль 2015 г., Гипатия имела 635 тыс. поисковых запросов, уступая только четырем философам: Платону (90 млн), Сократу (25 млн), Аристотелю (22 млн) и Пифагору (9,1 млн). При этом популярность Гипатии намного опережала неоплатоников Плотина (458 тыс.), Порфирия Тирского (65 тыс.), Ямвлиха (224 тыс.), Прокла (408 тыс.) и Дамаския (97,5 тыс.). Даже св. Кирилл Александрийский имел лишь 523 тыс. поисковых запросов [Watts, 2017, p. 4, 158].

В 2011 г. австрийский филолог Генриетта Харих-Шварцбауэр издала монографию «Гипатия. Позднеантичные источники» на основе своей диссертации, защищенной в 1997 г. В ней даётся филологическая критика основных источников по жизни и деятельности Гипатии [Harich- Schwarzbauer, 2011]. 
Также наблюдается усиление феминистического уклона в исследованиях по Гипатии. В этом ключе выполнена работа К. Минарди «Вспоминая древних женщин: Гипатия Александрийская и её сообщество» [Minardi, 2011]. Автор подчеркивает роль Гипатии в социальной и политической жизни, отмечает её публичную деятельность, участие в различных организациях, а также значимость вклада женщины в науку и культуру. Работа опирается на различные феминистические концепции и носит междисциплинарный характер.

Также вышла монографии Шарлотт Буз «Гипатия: математик, философ, миф» [Booth, 2017]. В этой книге автор разбирает существующие мифы о Гипатии, подчеркивая её элитное положение в обществе, и показывает её основные достижения. Гипатия представлена как яркая представительница египетской культуры, духовная наследница Клеопатры.

Новую и более подробную статью издал Алан Кэмерон под названием «Жизнь, работа и смерть Гипатии». Первоначально она вышла в 2013 г. в парижском сборнике в честь П. Шувена [Cameron, 2013, p. 65-82], а затем была переиздана под названием «Гипатия: жизнь, смерть и труды» (глава 9) в собственном сборнике Кэмерона «Странствующие поэты и другие очерки позднегреческой литературы и философии» [Cameron, 2016, p. 185-203]. Эта статья достаточно глубокая, она подробно и критически анализирует все источники о Гипатии, а также дает краткий обзор рецепции образа Гипатии в последующей исторической традиции. Автор критически оценивает идеи Э. Уоттса и приходит к выводу, что школа Гипатии не была так значима, как её представляют, так как у нее не было учеников, ставших профессиональными философами. Ориентируясь на уничижительные характеристики Гипатии как философа со стороны Дамаския, Кэмерон приходит к выводу, что Гипатия не внесла ничего нового в неоплатонизм. Она была традиционным платоником с интересом к священным мистериям Ямвлиха. Но и математические работы Гипатии сомнительны в плане самостоятельности, скорее, это редакция работ Теона. Кэмерон соглашается с М. Дикином, что это были комментарии и адаптация. Гипатия была скорее софистом и преподавателем, нежели фундаментальным учёным. В то же время благодаря своему высокому социальному положению Гипатия была действительно близка с высшими магистратами Александрии. Её убийство английский учёный связывает с политическими мотивами, а также с тем, что она оказывала влияние на правящий слой. Кирилл относился к ней отрицательно из-за того, что префект Орест хотел использовать её в качестве союзницы в борьбе с авторитетом александрийского патриарха, привлекая образованную языческую элиту. Сама Гипатия была довольно мудрой женщиной, но пожилой, - ей было уже за 60 на момент убийства, по мнению Кэмерона, и она не стремилась вмешиваться в христианско-иудейский конфликт, отстаивая интересы своей группировки.

Апологетическую позицию по отношению к св. Кириллу занимают австралийский исследователь Марио Багос [Baghos, 2014, p. 87-125] и польский учёный Анджей Холасек [Holasek, 2012, S. 107-113], которые полагают, что патриарх не был заинтересован в жестоком убийстве женщины-учёного, и нет никаких прямых доказательств его участия в этих событиях. В то же время тогда развертывалась борьба между христианскими группировками, а также иудеями, в ходе чего вспыхнули беспорядки, а сам Кирилл боролся против новациан. Основной источник, намекающий на участие патриарха в убийстве, - церковный историк Сократ Схоластик - имел новацианские симпатии и был тенденциозен в изображении Кирилла. Дамаский же в целом был настроен антихристиански.

В 2017 г. вышла еще одна крупная работа по Гипатии. Она была подготовлена уже упоминавшимся Эдвардом Уоттсом под названием «Гипатия. Жизнь и легенда античного философа» [Watts, 2017]. Эта работа более поверхностна, чем работа М. Дикина, в плане анализа математических штудий Гипатии. Несмотря на это, монография представляет собой довольно серьёзное историческое исследование, в ней присутствуют весьма важные моменты в плане источниковедения, исторического контекста и рецепции образа Гипатии. Эта работа также состоит из введения и 10 глав. Во введении автор дает яркую картину 
произошедшего убийства и вводит читателя в проблему, показывая шокирующий эффект убийства в ранневизантийском обществе как среди язычников, так и христиан, а также значимость образа Гипатии в современном мире. В 1 главе дается социальноисторический контекст событий жизни Гипатии. Автор показывает Александрию как город жестких социальных контрастов: живущее в античном антураже классически образованное меньшинство и бедное интернациональное необразованное большинство, живущее в тяжелых условиях. Во 2 главе рассматривается детство и образование Гипатии; автор делает вывод, что Гипатия училась у Теона, что повлияло на её философские взгляды. Философию она не сакрализировала, а сочетала с математическими знаниями. Также показываются возможности женского образования в поздней античности. В главе 3 показана школа Гипатии, которая изображается как основанная на математических штудиях, продолжая методы Теона, а также что философская составляющая образования следовала здесь традициям Плотина и Порфирия, обучение строилось на чтении и анализе философских текстов Платона и Аристотеля, без всяких религиозных практик. Уоттс отрицает ямвлихово влияние на трактаты Гипатии, призывая отделять её учение от концепций Синесия, следующего христианским гностикам [Watts, 2017, p. 45]. В то же время она давала высокие образцы морали и гражданственности. Отсутствие теургических практик привлекало в школу Гипатии христиан, а само образование было в религиозно нейтральном ключе, давая духовную пищу и для язычников, и для христиан. В главе 4 показывается процесс медиевализации образования, когда оно всё более наполнялось религиозным содержанием. Автор показывает упадок Афинской школы, а также развитие теургических практик на Востоке, в том числе в Александрии. Эти школы были конкурентами школы Гипатии, хранившей античные платонические традиции. Также показана религиозная борьба среди христиан и антиязыческие гонения, что приводило к радикализации язычества и нарастанию социальной напряженности. Глава 5 посвящена социальным связям в школе Гипатии между учителем и учениками, которые выступали как мать и её дети, на основе писем Синесия. Также затрагивается тема девственности Гипатии и распространения этих идей среди неоплатоников. В 6 главе рассматривается общественная деятельность Гипатии как часть гражданских обязательств и долга античного философа, хотя, по мнению Уоотса, политика Гипатию не интересовала. В качестве примера приводится философполитик IV в. Фемистий. В 7 главе дается краткая характеристика других известных женщин-философов, «сестер Гипатии», показывая возможности женского образования: это Пандросиона, Сосипатра и Асклепиогения, жена Максима Эфесского, хотя при этом жившая в середине V в. в Александрии женщина-философ Эдесия, глава школы Гермия [Болгов, Болгова, 2019], не упоминается. 8 глава посвящена убийству Гипатии, в том числе с анализом социально-политической жизни в городе накануне убийства, на основе источников, а также его значению и последствиям для Александрии. Убийство Гипатии автор связывает с социальной напряженностью в александрийском обществе и этносоциальными противоречиями. При этом, по мнению Уоттса, изначально Гипатию не собирались убивать, а лишь запугать, но сыграл свою роль эффект толпы [Watts, 2017, p. 115]. Также он делает вывод, что после убийства Гипатии Афины снова перехватили у Александрии пальму первенства в философской науке. В главе 9 показано восприятие убийства Гипатии и отражение его в последующей нарративной традиции средних веков как в византийской, так и на западе. Автор подчеркивает ужас современников и потомков, а также героический ореол, который получила Гипатия в результате своей трагической смерти. В то же время выделяется точка зрения Иоанна Никиусского, который чуть ли не единственный защищает патриарха Кирилла и обвиняет Гипатию. Одной из самых интересных глав является глава 10, посвященная рецепции образа Гипатии в последующей культуре и исторической науке вплоть до современности. Заключение представлено как анализ современных мифов о Гипатии, символизма её образа в современной политике и культуре. 
Книга Уоттса вызвала широкий отклик в научном сообществе, на неё было написано несколько рецензий - как положительных, так и отрицательных. Разгромную рецензию написала вышеупомянутая Сильвия Ронкей [Ronchey, 2018], критикующая Уоттса за умозрительность положений и выводов, что часто он игнорирует источники и выдает собственные идеи за доказанные положения. Критически разбирая положения Уоттса, Ронкей представляет собственные интересные идеи: например, оспаривая пожилой возраст Гипатии на момент смерти, исследовательница замечает, что история с менструальной кровью доказывает, что Гипатия была в детородном возрасте на момент преподавания, то есть до 40 лет, и ей приходилось отбиваться от влюбленных в неё студентов. Также Ронкей резко критикует умозрительные построения Уоттса относительно убийства Гипатии и игнорирование им политической составляющей этого убийства, выдвигая интересную концепцию о том, что убийство могло быть связано с опасениями Кирилла, что Гипатия формировала среди магистратов политическую группировку с целью антихристианского заговора. Поэтому убийство носило характер разгрома этой языческой партии.

В то же время весьма положительную рецензию на монографию Уоттса оставил А. Петкас, который хвалит автора за грамотную структуру, интересное содержание, особенно за вставку главы о других женщинах-ученых, делая замечание, что в книге недостаточно раскрыта риторическая составляющая в школе Гипатии [Petkas, 2018, p. 11-14].

Р. Брендель оставил в целом нейтральную рецензию, в качестве недостатков книги отметив слишком современный подход Уоттса к Гипатии с феминистических позиций и заметив, что в общественной жизни античности формы дискриминации с помощью слухов о сексуальной невоздержанности применялись к любым политическим противникам; а также сделав замечание о том, что у Уоттса указана не вся важная исследовательская литература [Brendel, 2018].

А вот исследовательница-феминистка Алесия Пицци, наоборот, похвалила автора за такое внимание к Гипатии как женщине, подчеркнув ее важную роль в позднеантичном обществе как примиряющей силы, а также отметив, что она была великой женщиной, которой выпала возможность сыграть мужскую роль [Pizzi, 2018].

Аналогичную хвалебную рецензию оставила Виктория Леонард [Leonard, 2018, p. 416-419], подчеркнувшая сбалансированность работы Уоттса в плане освещения жизни и деятельности Гипатии с гендерно нейтральных позиций; она сделала несколько любопытных замечаний о том, что все источники о Гипатии дошли от мужчин и носят женоненавистнический характер, а также что девственность Гипатии была не только данью философской традиции, но и платой - отказом от сексуальности - за возможность заниматься общественно-политической жизнью.

Также очень положительно оценила книгу и Роберта Мацца, которая назвала её «всесторонним социальным расследованием». В то же время она упрекнула автора в том, что он предпочитает ориентироваться на мужские древние источники о Гипатии, а не анализировать трудности положения женщины в позднеантичном обществе в современном дискурсе, подчеркнув величие Гипатии, которая смогла за счет таланта преодолеть все формы социальной дискриминации женщин, а также в образе своей школы создала некую контркультуру господствующей идеологии воинствующего христианства. За это она и поплатилась, как многие современные женщины, став жертвой мужского насилия [Mazza, 2018, p. 59-62].

Восторженную рецензию на книгу Уоттса оставил Седрик Шейдеггер Лёммле, подчеркнув, что Уоттс качественно справился с задачей реконструкции биографии Гипатии в условиях малочисленности и тенденциозности источников, а также что автор правильно уловил гендерную динамику в исследовании позднеантичного общества. Похвалы удостоились и последние главы, отражающие особенности рецепции мифа о Гипатии в Новое и Новейшее время [Lämmle, 2018, p. 170-172]. 
Литовская исследовательница Айсте Селкуте из Корейского университета в Сеуле также отзывается очень высоко об этой книге Уоттса, хотя её рецензия носит больше дескриптивный характер. Тем не менее она подчеркивает важность вопросов, которые поднимает Уоттс: о возможностях женского образования, о конкуренции Афинской и Александрийской философских школ в этот период, положительно отмечая главу о женщинахфилософах, которая позволяет выделить общие проблемы, с которыми сталкивались женщины-учёные в поздней античности. В то же время Селкуте считает, что основным залогом успеха Гипатии на общественно-политическом и научном поприще было её социальное положение и то, что она являлась дочерью Теона и унаследовала его школу, а отнюдь не её талант, так как для женщин в тот период было слишком много социальных ограничений, чтобы пробиться за счёт одного таланта [Čelkytė, 2018].

Особняком стоит статья Кристин Сампсон «Известная и забытая Гипатия» [Sampson, 2018, S. 53-65], которая использует монографию Уоттса как фон для рассуждений о том, какие мифы существуют про Гипатию, а какие стороны её жизни и деятельности полностью проигнорированы. В этой статье исследовательница приходит к интересной идее о том, что возвышение неоплатонической школы Гипатии в начале V в. связано с разгромом языческой оппозиции при закрытии храма Сераписа в 391 г., так как тогда все конкурирующие с Гипатией представители философского теургического направления покинули город.

Новые публикации по Гипатии продолжают появляться в большом количестве и в последнее время. Отметим вышедшую в 2017 г. интересную статью американских исследователей о новых методах определения даты рождения Гипатии на основе математических принципов [Canio, Isola, Russo, 2017, p. 19-40].

Помимо данных работ продолжает развиваться направление исследования образа Гипатии в области античной рецепции. Особое внимание современных исследователей привлекает вышеупомянутый фильм «Агора» как вариант исторической реконструкции жизни Гипатии. Несмотря на то, что в «Агоре» допущены многие вольности, искажающее информацию из первоисточников (например, Гипатия на момент убийства представлена как молодая и красивая женщина; её убивает не толпа по-зверски, а мягко её бывший раб, влюбленный в неё и ставший христианином, чтобы спасти от жестокой расправы и надругательства; префект Орест является её бывшим учеником и тем самым неудачным влюбленным, которому она демонстрировала менструальную кровь; Синесий на момент обучения уже является христианином; перенос убийства Гипатии на 24 года назад, во времена разрушения храма Сераписа и пожара в Александрийской библиотеке и т. п.). Тем не менее в «Агоре» очень хорошо показан исторический фон позднеантичной Александрии и степень напряженности борьбы между различными религиозными конфессиями, а различные искажения хорошо показывают стереотипы современного общества о Гипатии. Образу Гипатии в «Агоре» посвящена вышедшая в 2014 г. статья Марии Лопес Мартинес [Martnez, 2014, p. 202-222]. Также вышли и другие статьи с отзывами на этот фильм.

В 2016 г. была защищена диссертация южноафриканской исследовательницы Джиллиан ван дер Хейден «Исследование рецепции жизни и смерти философанеоплатоника Гипатии Александрийской в фильме Аменабара "Агора“». Эта диссертация включает в себя введение и 7 глав. В главе 1 исследуется исторический контекст Александрии 370-415 гг. В главе 2 дан обзор литературы: как источников (помимо привычных источников, в том числе игнорируемая многими исследователями эпиграмма поэта $\mathrm{V}$ в. Паллада на Гипатию), так и исследований (вынесены в отдельные разделы работы Толанда, Гиббона, Риста, Видера, Пенеллы, Дзельской, Дикина и Кэмерона) и наиболее значимых произведений художественной литературы (роман Ч. Кингсли «Гипатия»). В главе 3 анализируются наиболее значимые исторические фильмы-пеплумы об античности как предтечи «Агоры», а также рецепция этих образов в современной культуре и идеологии. Глава 4 посвящена уже конкретному разбору фильма Аменабара «Агора», архитектурно- 
му пространству, развитию сюжета, основным конфликтам. В главе 5 дается характеристика основному антагонисту - архиепископу Кириллу, а также его окружению, в том числе оказавшемуся в другом лагере Синесию, а также рецепции классической античности в христианскую эпоху, представленной в фильме. В главе 6 представлен образ одного из главных протагонистов наравне с Гипатией - раба Дава. Этот персонаж не является исторической личностью, но его глазами зритель может видеть обе противоборствующие стороны как бы изнутри. Глава 7 является заключением [Heijden, 2016]. Исследования этого фильма очень важны, так как именно через «Агору» современный зритель может визуализировать эпоху Гипатии.

\section{Заключение}

Таким образом, тема Гипатии является одной из ключевых в современной историографии поздней античности. Это связано с популярностью образа женщины-философа в современной культуре, она является самой популярной среди всех позднеантичных философов, а среди всех философов древности идёт на пятом месте, уступая только Платону, Сократу, Аристотелю и Пифагору. Это связано не столько с научными заслугами Гипатии, от которой дошли лишь комментарии, и то лишь частично (нет ни одной самостоятельной работы), сколько с необычным для её пола высоким положением в позднеантичном социуме Александрии (она возглавляла крупнейшую философскую школу города и была на короткой ноге с местными правителями), а также жестоким убийством, сделавшим её мученицей язычества. Образ Гипатии как женщины-философа стал привлекать внимание ещё в XVIII в. в науке, так как был необычайно подходящим в плане антиклерикальной направленности творчества философов и гуманистов эпохи Просвещения, получив распространение в культуре и искусстве, поскольку в качестве виновника гибели талантливой женщины-философа подозревается один из столпов догматики - св. патриарх Кирилл Александрийский. Интерес к Гипатии проявлялся в XIX в., когда были созданы первые фундаментальные работы по её жизни и творчеству, которые можно считать научными. Он также не угасал в 1-й пол. ХХ в., но до 1960-х гг. практически не было создано крупного труда о Гипатии, кроме отдельных статей, что было связано с трудностью анализа математических штудий Гипатии. Но во 2-й пол. XX в. начался исследовательский бум в отношении Гипатии, который особенно активизировался с 1990-х гг. Именно тогда были созданы первые фундаментальные монографии о её жизни и творчестве. На данный момент лучшими и наиболее системными работами о Гипатии являются монографии М. Дзельской, М. Дикина, где впервые комплексно анализируются математические штудии женщины-учёного, Э. Уоттса, а также глубокие статьи Ал. Кэмерона. В наши дни исследовательский интерес к проблеме продолжает расти. Этому способствовало развитие образа Гипатии в культуре и искусстве, в том числе и появление на экранах испанского фильма «Агора», ставшего первым фильмом, где в центре внимания был конфликт Гипатии с патриархом Кириллом Александрийским. География исследований охватывает практически весь мир, все европейские научные школы, продолжая расширяться: среди разобранных нами работ есть работы английских, французских, немецких, австрийских, итальянских, испанских, бельгийских, нидерландских, норвежских, финских, польских, американских, австралийских, южноафриканских учёных, а также представителей южнокорейских научных центров. Из новейших работ наиболее важной является монография Э. Уоттса, которая получила широкий отклик и множество рецензий, в основном положительных. Основные современные тенденции изучения образа Гипатии - это, помимо классических тем, изучение убийства Гипатии в контексте конфликта с Кириллом Александрийским, изучение её научных математических и астрономических работ, исследование её философского учения в контексте неоплатонизма; новые темы и направления: изучение личности, общественного положения и политической деятельности Гипатии с феминистических позиций как женщины-философа, изучение рецепции образа Гипатии в последую- 
щие эпохи, в частности в современной культуре. Еще одной тенденцией стала междисциплинарность исследований. Они не только касаются истории, но и математики, культурологии, социологии, гендерной психологии.

\section{Список сокращений}

$\begin{array}{lll}\text { Anthol. Gr. } & \text { Anthologia Craeca } & \text { «Палатинская Антология» } \\ \text { Damasc. } & \text { Damascius, Vita Isidori } & \text { Дамаский, «Жизнь Исидора» } \\ \text { Ioan. Nik. Chron. } & \text { Ioannes Nikiûensis, Chronicon } & \text { Иоанн Никиусский, «Хроника» } \\ \text { Malal. Chron. } & \text { Ioannes Malalas, Chronographia } & \text { Иоанн Малала, «Хронография» } \\ \text { Philostorg. HE. } & \text { Philostorgius, Historia Ecclesiastica } & \text { Филосторгий, «Церковная история» } \\ \text { Socr. HE. } & \text { Socrates Scholasticus, Historia Ecclesiastica } & \text { Сократ Схоластик, «Церковная история» } \\ \text { Suid. } & \text { Suida Lexicon } & \text { Словарь «Суда» } \\ \text { Theoph. Chron. } & \text { Theophanes, Chronicon } & \text { Феофан, «Летопись» }\end{array}$

\section{Список литературы}

1. Болгов Н.Н., Болгова А.М. 2019. Александрийские школы V в. по «Философской истории» Дамаския. В: ИРЕСИОНА. Античный мир и его наследие. Вып. VI. Материалы научной сессии кафедры всеобщей истории к 40-летию начала антиковедческих исследований. Белгород, НИУ «БелГУ»: 105-136.

2. Дорофеева В.А., Высокий М.Ф., Тимофеев М.А. (изд.). 2007. Филосторгий. Сокращение «Церковной истории». В: Церковные историки IV-V веков. Москва, РОССПЭН: 187-262, 520-584.

3. Кривушин И.В. (изд.). 1996. Сократ Схоластик. Церковная история. Москва, РОССПЭН, 368.

4. Оболенский В.И., Терновский Ф.А., Бодянский О.М. (изд.). 1884. Летопись византийца Феофана от Диоклетиана до царей Михаила и сына его Феофилакта. Москва, Ун-т типогр. на Страстн. б-ре М. Каткова, 370.

5. Asmus R. 1907. Hypatia in Tradition und Dichtung. In: Studien zur vergleichenden Literaturgeschichte. 7: 26-27.

6. Baghos M. 2014. Ecclesial Memory and Secular History in the Conflicting Representations of Cyril of Alexandria: An Apology for the Saint. In: PHRONEMA. Vol. 29 (2): 87-125.

7. Barry W.D. 1996. Roof Tiles and Urban Violence in the Ancient World. In: Greek, Roman, and Byzantine Studies. 37: 55-74.

8. Bekker I. (ed.). 1854. Suidae Lexicon. Berolini typis et impensis G. Reimeri, 1158.

9. Belenkiy A. 2010. An Astronomical Murder? In: Astronomy and Geophysics. 51.2: 9-13.

10. Bernard A. 2010. Theon of Alexandria and Hypatia. In: The Cambridge History of Philosophy in Late Antiquity. Vol. 1. Cambridge: 417-436.

11. Bigoni G. 1886/1887. Ipazia Alessandrina Studio Storico. In: Atti del R. ist. Veneto di scienze, lettere ed arti. 6 ser. 5: 397-437, 495-526, 681-710.

12. Booth C. 2017. Hypatia: Mathematician, Philosopher, Myth. UK \& USA: Fonthill, 192.

13. Brendel R. [Rezension zu]: Watts, Edward J. Hypatia. The Life and Legend of an Ancient Philosopher (Women in Antiquity). New York 2017: Oxford University Press. XII, 205 S. In: H-SozKult. URL: https://www.hsozkult.de/publicationreview/id/reb-26192 (дата обращения 17.02.2021).

14. Cameron A. 2013. The Life, Work and Death of Hypatia. In: Le Voyage des légendes: Hommages à Pierre Chuvin. Paris: 65-82.

15. Cameron Al. 1990. Isidore of Miletus and Hypatia: On the Editing of Mathematical Texts. In: Greek, Roman and Byzantine Studies. 31: 103-127.

16. Cameron Al. 2016. Hypatia: Life, Death, and Works. In: Wandering Poets and Other Essays on Late Greek Literature and Philosophy. Oxford: Oxford University Press: 185-203.

17. Cameron Al., Long J. 1993. Barbarians and Politics at the Court of Arcadius. Berkeley, 440.

18. Canio B., Isola S., Russo L. 2017. Dating Hypatia's birth: a probabilistic model. In: Mathematics and Mechanics of Complex Systems. T. 5 (1): 19-40.

19. Čelkytė A. 2017. [Review]: Watts, Edward J. Hypatia: the life and legend of an ancient philosopher. Women in antiquity. New York: Oxford University Press, 2017. xii, 205 p. In: Bryn Mawr 
Classical Review. URL: http://www.bmcreview.org/2017/10/20171007.html (дата обращения 17.02.2021).

20. Charles R.H. (ed.). 1916. The Chronicle of John, bishop of Nikiu. Trans. from Zotenberg's ethiopic text. London: Society by Williams \& Norgate, 216.

21. Cribiore R. 2007. Spaces for Teaching in Late Antiquity. In: Alexandria Auditoria of Kôm el-Dikka and Late Antique Education. Warsaw: 143-150.

22. Deakin M.A.B. 2007. Hypatia of Alexandria. Matematician and Martyr. New York: Prometheus Books, 231.

23. Desmolets P.-N. (ed.). 1749a. Dissertation sur Hypacie, où l'on justifie Saint Cyrille d'Alexandrie sur la mort de cette Sçavante. In: Continuation des Mémoires de Litterature et d'Histoire. 5.1: 139-186.

24. Desmolets P.-N. (ed.). 1749b. Lettre de Mademoiselle B. à M. G. sur la Dissertation précedente (1728). In: Continuation des Mémoires de Litterature et d'Histoire. 5.1: 187-191.

25. Donovan S. 2008. Hypatia: Mathematician, Inventor, and Philosopher. Mankato (MN): Compass Point books, 112.

Press, 157.

26. Dzielska M. 1995. Hypatia of Alexandria. Cambridge, Massachusetts, Harvard University

27. Évrard É. 1977. A quel titre Hypatie enseigna-t-elle la philosophie? In: Revue des Études Grecques. 90: 69-74.

28. Gibbon E. 1781. The History of the Decline and Fall of the Roman Empire. In 6 vols. Vol. III. London, Strahan \& Cadell, 643.

29. Haas C. 1997. Alexandria in Late Antiquity. Topography and Social Conflict. Baltimore and London, The Johns Hopkins University Press, 497.

30. Harich-Schwarzbauer H. 2011. Hypatia: Die spätantiken Quellen. Eingeleitet, kommentiert, und interpretiert. Bern, Lang, 397.

31. Heijden G. 2016. Study of the Reception of the Life and Death of the Neoplatonist Philosopher Hypatia of Alexandria in Amenabar's Film Agorá. Durban, University of Kwazulu-Natal, 140.

32. Heikura P.T. 2000. Kuka murhasi filosofi Hypatian? Piispa Kyrillos ja Hypatian kuolema. In: Niin \& näin. 4: 30-33.

33. Hoche R. 1860. Hypatia, die Tochter Theons. In: Philologus. 15 (1-3): 435-74.

34. Holasek A. 2012. Rola pontyfikatu Cyryla (412-444) w procesie umacniania potegi patriarchy aleksandryjskiego w kosciele. In: Vox Patrum. 32. T. 58: 107-113.

35. Hypatia: A Journal of Feminist Philosophy. In: Cambridge University Press. URL: https://www.cambridge.org/core/journals/hypatia (дата обращения 17.02.2021).

36. Kaplow L. 2005/2006. Religious and Intercommunal Violence in Alexandria in the 4th and 5th centuries C. E. In: Hirundo, the McGill Journal of Classical Studies. Vol. 4: 2-26.

37. Knorr W.R. 1989. Textual Studies in Ancient and Medieval Geometry. Boston, Birkhäuser, 864.

38. Kramer C. 2006. Holy Murder: The Death of Hypatia of Alexandria. Concord, Massachusetts, Infinity Publishing, 284.

39. Lämmle C.S. 2018. [Review]: Hypatia: The Life and Legend of an Ancient Philosopher. By Edward J. Watts. New York, Oxford University Press (Women in Antiquity). 2017. Pp. xii, 205. In: Phoenix. 72.1/2: 170-172.

40. Leonard V. 2017. [Book Reviews]: Edward J. Watts. Hypatia: The Life and Legend of an Ancient Philosopher. Women in Antiquity. New York, Oxford University Press, 2017. Pp. 224. In: Studies in Late Antiquity. Winter: 416-419.

41. Lewis T. 1721. The History of Hypatia, A Most Impudent School- Mistress of Alexandria: Murder'd and Torn to Pieces by the Populace, in Defence of Saint Cyril and the Alexandrian Clergy. From the Aspersions of Mr. Toland. London, 44.

42. Majcherek G. 2007. The Late Roman Auditoria: An Archeological Overview. In: Alexandria Auditoria of Kôm el-Dikka and Late Antique Education. Warsaw: 11-50.

43. Marrou H.I. 1952. La 'conversion’ de Synésios. In: Revue des Études Grecques. 65: 474-84.

44. Marrou H.I. 1964. Synesius of Cyrene and Alexandrian Neoplatonism. In: The Conflict between Paganism and Christianity in the Fourth Century. Oxford, Clarendon: 126-150.

45. Martinez M.L. 2014. «Había una mujer en Alejandría que se llamaba Hipatia»: su presencia en Agora de Amenábar. In: Asparkía. 25: 202-222. 
46. Mazza R. 2018. [Review]: Edward J. Watts, Hypatia: The Life and Legend of an Ancient Philosopher. Oxford, Oxford University Press, 2017. Pp. 224. In: New England Classical Journal. Vol. 45. Issue 1: 59-62.

47. McKenzie J. 2007. The Architecture of Alexandria and Egypt, 300 B. C. - 700 A. D. New Haven and London, Yale University Press: 460.

48. Medicci J.M., de. 2007. The Beloved and the Damned: Hypatia and Cyril from late Antiquity through Modernity. M.A. Thesis. University of Wisconsin - Eau Claire, 155.

49. Meyer W.A. 1886. Hypatia von Alexandria: Ein Beitrag zur Geschichte des Neuplatonismus. Heidelberg, Weiss, 52.

50. Minardi C. 2011. Re-Membering Ancient Women: Hypatia of Alexandria and Her Communities. Atlanta, University of Georgia: 234.

51. Mueller I. 1987. Hypatia. In: Women of Mathematics: A Biobibliographic Sourcebook. Westport, CT, Greenwood: 74-79.

52. Neugebauer O. 1949. The Early History of the Astrolabe. In: Isis. 40: 240-256.

53. Neugebauer O. 1975. A History of Ancient Mathematical Astronomy. Berlin, Springer, 1457.

54. Nietupski N. 1993. Hypatia of Alexandria: Mathematician, Astronomer, and Philosopher. In: Alexandria. The Journal of the Western Cosmological Traditions. 2: 46-62.

55. Paton W.R. (ed.). 1917. The Greek Antology with an English translation. In 5 vols. Vol. III (Book IX). London, William Heinemann; New York, G.P. Putnam's Sons, 456.

56. Penella R.J. 1984. When Was Hypatia Born? In: Historia. 33: 126-128.

57. Petkas A. 2018. [Review]: Edward J. Watts, Hypatia: the Life and Legend of an Ancient Philosopher. New York, Oxford University Press, 2017. Pp. xii $+205 ; 9$ illustrations. In: Ancient History Bulletin. 8: 11-14.

58. Pizzi A. [Review]: Hypatia: The Life and Legend of an Ancient Philosopher. Edward J. Watts. In: CulturaMente. URL: https://www.culturamente.it/wp-content/uploads/2017/11/E.J.-WattsHypatia-book-review-by-Alessia-Pizzi-Culturamente.it_pdf (дата обращения 17.02.2021).

59. Rashed R. 1974. Les travaux perdus de Diophante I, II. In: Revue d'Histoire des Sciences. 27: $97-122$. 28: $3-30$.

60. Rashed R. 1975. Les travaux perdus de Diophante I, II. In: Revue d'Histoire des Sciences.

61. Richeson A.W. 1940. Hypatia of Alexandria. In: National Mathematics Magazine. 15: 74-82.

62. Rist J.M. 1965. Hypatia. In: Phoenix. 19.3: 214-225.

63. Rome A. 1926. Le troisième livre sur l'Almagest par Théon et Hypatie. In: Annales de la Société Scientifique de Bruxelles. 46: 1-14.

64. Ronchey S. 1999. Hypatia the Intellectual. In: Roman Women. Chicago: 160-189.

65. Ronchey S. 2005. Adoring Hypatia. Platonic Love, or the Conflicting Emotions a Byzantine Teacher May Arouse. In: Porphyra. n. 6. Bisanzio, narrazione di una civiltà colta: 129-138.

66. Ronchey S. 2018. [Review]: Accidental death of a professor. On a recent book on Hypatia E.J. Watts, Hypatia. The Life and Legend of an Ancient Philosopher, Oxford, Oxford University Press, 2017, pp. i-xii, 1-205. In: Silvia Ronchey Docenza. URL: http://www.silviaronchey.it/docenza/2/160/Accidental-Death-of-a-Professor-On-a-Recent-Book-onHypatia-E-J-Watts-Hypatia-The-Life-and-Legend-of-an-Ancient-Phi/ (дата обращения 17.02.2021).

67. Roques D. 1995. La Famille d'Hypatie. In: Revue des Études Grecques. 108: 128-149.

68. Sampson K. 2018. Den kjente og den glemte Hypatia. In: Norsk Filosofisk Tidsskrift. ÅRGANG 53, NR. 2-3: 53-65.

69. Seeck O. 1966. Geschichte des Untergangs der antiken Welt, 6 Bände. Bd. 6. Darmstadt, Wissenschaft liehe Buchgesellschaft.

70. Tannery P. 1880. L'article de Suidas sur Hypatie. In: Annales de la Faculté des Lettres de Bordeaux. 2: 197-200.

71. Toland J. 1753. Hypatia: Or, the History of a most beautiful, most vertuous, most learned, and every way accomplish'd Lady; who was torn to Pieces by the Clergy of Alexandria, to gratify the Pride, Emulation, and Cruelty of their Archbishop, commonly but undeservedly stiled St. Cyril. London, 36.

72. Voltaire F.-M. A. 1860. Hipathie. In: Dictionnaire philosophique. Oeuvres complètes de Voltaire: Nouvelle édition. Vol. 13. Paris: 585-586. 
73. Waithe M.E. 1987. A History of Women Philosophers. Vol. 1: Ancient Women Philosophers, 600 B.C.-500 A.D. Dordrecht, Nijhoff, 229.

74. Watts E.J. 2006. City and School in Late Antique Athens and Alexandria. Berkeley, Los Angeles, London, University of California Press, 288.

75. Watts E.J. 2017. Hypatia. The Life and Legend of an Ancient Philosopher. Oxford, Oxford University Press, 205.

76. Whitfield B.J. 1995. The Beauty of Reasoning: A Reexamination of Hypatia and Alexandria. In: The Mathematics Educator. T. 6 (1): 14-21.

77. Wolf S. 1879. Hypatia, die Philosophin von Alexandrien: Ihr Leben, Wirken und Lebensende nach den Quellenschriften dargestellt. Vienna, Holder, 41.

\section{References}

1. Bolgov N.N., Bolgova A.M. 2019. Aleksandrijskie shkoly V v. po «Filosofskoj istorii» Damaskiya [Alexandrian schools of the 5th century on the «Philosophical History» of Damascius]. In: IRESIONA. Antichnyj mir i ego nasledie [IRESIONA. The ancient world and its heritage]. Issue 6. Materialy nauchnoj sessii kafedry vseobshchej istorii k 40-letiyu nachala antikovedcheskih issledovanij [Materials of the Scientific Session of the Department of General History on the 40th Anniversary of the Beginning of Antiquarian Studies]. Belgorod, NIU «BelGU», 105-136 (in Russian).

2. Dorofeeva V.A., Vysokij M.F., Timofeev M.A. (ed.). 2007. Filostorgij. Sokrashchenie «Cerkovnoj istorii» [Philostorgius. Abbreviation of «Church History»]. In: Cerkovnye istoriki IV-V vekov [Church Historians 4-5 centuries]. Moscow, ROSSPEN: 187-262, 520-584 (in Russian).

3. Krivushin I.V. (ed.). 1996. Sokrat Skholastik. Cerkovnaya istoriya [Socrates Scholasticus. Church History]. Moscow, ROSSPEN, 368 (in Russian).

4. Obolenskij V.I., Ternovskij F.A., Bodyanskij O.M. (ed.). 1884. Letopis' vizantijca Feofana ot Diokletiana do carej Mihaila i syna ego Feofilakta [Chronicle of the Byzantine Theophanes from Diocletian to tsars Michael and his son Theophylactus]. Moscow, Un-t tipogr. na Strastn. b-re M. Katkova, 370 (in Russian).

5. Asmus R. 1907. Hipatia in Tradicion und Dihtung [Hypatia in tradition and poetry]. In: Shtudin cur ferglajhenden Literaturgeshihte [Studies on the comparative history of literature]. 7: 26-27 (in German).

6. Baghos M. 2014. Ecclesial Memory and Secular History in the Conflicting Representations of Cyril of Alexandria: An Apology for the Saint. In: PHRONEMA. Vol. 29 (2): 87-125.

7. Barry W.D. 1996. Roof Tiles and Urban Violence in the Ancient World. In: Greek, Roman, and Byzantine Studies. 37: 55-74.

8. Bekker I. (ed.). 1854. Suidae Lexicon. Berolini typis et impensis G. Reimeri, 1158.

9. Belenkiy A. 2010. An Astronomical Murder? In: Astronomy and Geophysics. 51.2: 9-13.

10. Bernard A. 2010. Theon of Alexandria and Hypatia. In: The Cambridge History of Philosophy in Late Antiquity. Vol. 1. Cambridge: 417-436.

11. Bigoni G. 1886/1887. Ipacia Alessandrina Studio Storiko [Hypatia Alessandrina Historical Study]. In: Atti del' R. ist. Veneto di sh'ence, lettere ed arti [Proceedings of the R. ist. Veneto of sciences, letters and arts]. 6 ser. 5: 397-437, 495-526, 681-710 (in Italian).

12. Booth C. 2017. Hypatia: Mathematician, Philosopher, Myth. UK \& USA: Fonthill, 192.

13. Brendel R. 2021 [Rezension zu]: Watts, Edward J. Hypatia. The Life and Legend of an Ancient Philosopher (Women in Antiquity). New York 2017: Oxford University Press. XII, 205 S. In: HSoz-Kult. Available at: https://www.hsozkult.de/publicationreview/id/reb-26192 (accessed 17 February 2021).

14. Cameron A. 2013. The Life, Work and Death of Hypatia. In: Le Voyage des légendes: Hommages à Pierre Chuvin. Paris: 65-82.

15. Cameron Al. 1990. Isidore of Miletus and Hypatia: On the Editing of Mathematical Texts. In: Greek, Roman and Byzantine Studies. 31: 103-127.

16. Cameron Al. 2016. Hypatia: Life, Death, and Works. In: Wandering Poets and Other Essays on Late Greek Literature and Philosophy. Oxford, Oxford University Press: 185-203.

17. Cameron Al., Long J. 1993. Barbarians and Politics at the Court of Arcadius. Berkeley, 440.

18. Canio B., Isola S., Russo L. 2017. Dating Hypatia's birth: a probabilistic model. In: Mathematics and Mechanics of Complex Systems. T. 5 (1): 19-40. 
19. Celkyte A. 2017. [Review]: Watts, Edward J. Hypatia: the life and legend of an ancient philosopher. Women in antiquity. New York, Oxford University Press, 2017. XII, 205 p. In: Bryn Mawr Classical Review. Available at: http://www.bmcreview.org/2017/10/20171007.html (accessed 17 February 2021).

20. Charles R.H. (ed.). 1916. The Chronicle of John, bishop of Nikiu. Trans. from Zotenberg's ethiopic text. London: Society by Williams \& Norgate, 216.

21. Cribiore R. 2007. Spaces for Teaching in Late Antiquity. In: Alexandria Auditoria of Kôm el-Dikka and Late Antique Education. Warsaw: 143-150.

22. Deakin M.A.B. 2007. Hypatia of Alexandria. Matematician and Martyr. New York, Prometheus Books, 231.

23. Desmole P.-N. (ed.). 1749a. Disertas'on sur Ipas'e, u l'on zhustif'e Sen Siril' d'Alesanr'e sur lya mor de set Savan [Dissertation on Hypatia, in which Saint Cyril of Alexandria is justified on the death of this scholar]. In: Kontinuas'on de Memuar de Literatur e d'Istuar [Continuation of the Memoirs of Literature and History]. 5.1: 139-186 (in French).

24. Desmole P.-N. (ed.). 1749b. Letr de Madmuazel' B. a M.G. sur lya Disertas'on preseden (1728) [Letter from Miss B. to M. G. on the previous Dissertation (1728)]. In: Kontinuas'on de Memuar de Literatur e d'Istuar [Continuation of the Memoirs of Literature and History]. 5.1: 187-191 (in French).

25. Donovan S. 2008. Hypatia: Mathematician, Inventor, and Philosopher. Mankato (MN), Compass Point books, 112.

Press, 157.

26. Dzielska M. 1995. Hypatia of Alexandria. Cambridge, Massachusetts, Harvard University

27. Evrar E. 1977. A kel titr Ipas'e ansen'a-t-el lya filosof'e [How did Hypatia teach philosophy?]. In: Rev'yu des Etyud Greke [Journal of Greek Studies]. 90: 69-74 (in French).

28. Gibbon E. 1781. The History of the Decline and Fall of the Roman Empire. In 6 vols. Vol. III. London, Strahan \& Cadell, 643.

29. Haas C. 1997. Alexandria in Late Antiquity. Topography and Social Conflict. Baltimore and London, The Johns Hopkins University Press, 497.

30. Harih-SHvarcbauer H. 2011. Hipatia: Di shpetantiken Kvellen. Ajngelajtet, kommentirt, und interpretirt [Hypatia: The late antique sources. Introduced, commented, and interpreted]. Bern, Lang, 397. (in German).

31. Hejden G. 2016. Study of the Reception of the Life and Death of the Neoplatonist Philosopher Hypatia of Alexandria in Amenabar's Film Agorá. Durban, University of Kwazulu-Natal, 140.

32. Hejkura P.T. 2000. Kuka murhasi filosofi Hyupatian? Riispa Kyurillos ya Hyupatian kuolema [Who murdered the philosopher Hypatian? Bishop Cyril and the Death of Hypatia]. In: Niin \& nyajn [So \& so]. 4: 30-33 (in Finnish).

33. Hohe R. 1860. Hipatia, di Tohter Teons [Hypatia, Theon's daughter]. In: Philologus. 15 (1-3): 435-474 (in German).

34. Holyasek A. 2012. Rolya pontyfikatu Cyrylya (412-444) v procese umacnyanya potegi patryarhy aleksandryjskego $\mathrm{v}$ koscele [The role of the pontificate of Cyril (412-444) in the process of strengthening the power of the Alexandrian Patriarch in the church]. In: Vox Patrum. 32. T. 58: 107-113 (in Polish).

35. Hypatia: A Journal of Feminist Philosophy. In: web-site Cambridge University Press. Available at: https://www.cambridge.org/core/journals/hypatia (accessed 17 February 2021).

36. Kaplow L. 2005/2006. Religious and Intercommunal Violence in Alexandria in the 4th and 5th centuries C. E. In: Hirundo, the McGill Journal of Classical Studies. Vol. 4: 2-26.

37. Knorr W.R. 1989. Textual Studies in Ancient and Medieval Geometry. Boston, Birkkhojzer, 864.

38. Kramer C. 2006. Holy Murder: The Death of Hypatia of Alexandria. Concord, Massachusetts, Infinity Publishing, 284.

39. Lemle C.S. 2018. [Review]: Hypatia: The Life and Legend of an Ancient Philosopher. By Edward J. Watts. New York, Oxford University Press (Women in Antiquity). 2017. P. XII, 205. In: Phoenix. 72.1/2: 170-172.

40. Leonard V. 2017. [Book Reviews]: Edward J. Watts. Hypatia: The Life and Legend of an Ancient Philosopher. Women in Antiquity. New York, Oxford University Press, 2017. 224 p. In: Studies in Late Antiquity. Winter: 416-419. 
41. Lewis T. 1721. The History of Hypatia, A Most Impudent School-Mistress of Alexandria: Murder'd and Torn to Pieces by the Populace, in Defence of Saint Cyril and the Alexandrian Clergy. From the Aspersions of Mr. Toland. London, 44.

42. Majcherek G. 2007. The Late Roman Auditoria: An Archeological Overview. In: Alexandria Auditoria of Kôm el-Dikka and Late Antique Education. Warsaw: 11-50.

43. Marru H.I. 1952. Lya "konvers'o" de Sines'o. In: Rev'yu des Etyud Greke [Journal of Greek Studies]. 65: 474-484 (in French).

44. Marru H.I. 1964. Synesius of Cyrene and Alexandrian Neoplatonism. In: The Conflict between Paganism and Christianity in the Fourth Century. Oxford, Clarendon: 126-150.

45. Martines M.L. 2014. «Abiya una muher en Alekhandriya ke se l'yamaba Ipatiya»: su presensiya en Agora de Amenabar [«There was a woman in Alexandria called Hypatia»: her presence in Agora de Amenábar]. In: Asparkía [Asparkia]. 25: 202-222 (in Spanish).

46. Macca R. 2018. [Review]: Edward J. Watts, Hypatia: The Life and Legend of an Ancient Philosopher. Oxford: Oxford University Press, 2017. Pp. 224. In: New England Classical Journal. Vol. 45. Issue 1: 59-62.

47. McKenzie J. 2007. The Architecture of Alexandria and Egypt, 300 B. C. - 700 A. D. New Haven and London, Yale University Press: 460.

48. Medicci J.M., de. 2007. The Beloved and the Damned: Hypatia and Cyril from late Antiquity through Modernity. M.A. Thesis. University of Wisconsin - Eau Claire, 115.

49. Mejer W.A. 1886. Hipatia fon Aleksandria: Ajn Bajtrag cur Geshihte des Nojplatonismus [Hypatia of Alexandria: A Contribution to the History of Neoplatonism]. Heidelberg, Vajss, 52 (in German).

50. Minardi C. 2011. Re-Membering Ancient Women: Hypatia of Alexandria and Her Communities. Atlanta, University of Georgia: 234.

51. Mueller I. 1987. Hypatia. In: Women of Mathematics: A Biobibliographic Sourcebook. Westport, CT, Greenwood: 74-79.

52. Neugebauer O. 1949. The Early History of the Astrolabe. In: Isis. 40: 240-256.

53. Neugebauer O. 1975. A History of Ancient Mathematical Astronomy. Berlin, Springer, 1457.

54. Nietupski N. 1993. Hypatia of Alexandria: Mathematician, Astronomer, and Philosopher. In: Alexandria. The Journal of the Western Cosmological Traditions. 2: 46-62.

55. Paton W.R. (ed.). 1917. The Greek Antology with an English translation. In 5 vols. Vol. III (Book IX). London, William Heinemann; New York: G.P. Putnam's Sons, 456.

56. Penella R.J. 1984. When Was Hypatia Born? In: Historia. 33: 126-128.

57. Petkas A. 2018. [Review]: Edward J. Watts, Hypatia: the Life and Legend of an Ancient Philosopher. New York, Oxford University Press, 2017. Pp. XII + 205; 9 illustrations. In: Ancient History Bulletin. 8: 11-14.

58. Picci A. [Review]: Hypatia: The Life and Legend of an Ancient Philosopher. Edward J. Watts. In: web-site «CulturaMente». Available at: https://www.culturamente.it/wpcontent/uploads/2017/11/E.J.-Watts-Hypatia-book-review-by-Alessia-Pizzi-Culturamente.it_.pdf (accessed 17 February 2021).

59. Rashe R. 1974. Le travo perdu de D'ofan I, II [The lost works of Diophantus I, II]. In: Revue d'Histoire des Sciences. 27: 97-122 (in French).

60. Rashe R. 1975. Le travo perdu de D'ofan I, II [The lost works of Diophantus I, II]. In: Rev'yu d'Istuar de S'ens. [Journal of the History of Sciences]. 28: 3-30 (in French).

61. Richeson A.W. 1940. Hypatia of Alexandria. In: National Mathematics Magazine. 15: 74-82.

62. Rist J.M. 1965. Hypatia. In: Phoenix. 19.3: 214-225.

63. Rome A. 1926. Le truas'em livr sur l'Almazhes par Teo e Ipas'e [The third book on Almagest by Théon and Hypatie]. In: Annal de lya Sos'ete S'ensifik de Brusels [Annals of the Scientific Society of Brussels]. 46: 1-14 (in French).

64. Ronchey S. 1999. Hypatia the Intellectual. In: Roman Women. Chicago: 160-189.

65. Ronkej S. 2005. Adoring Hypatia. Platonic Love, or the Conflicting Emotions a Byzantine Teacher May Arouse. In: Porphyra. n. 6. Bizancio, narracione di una chivil'ta kol'ta [Byzantium, narration of a cultured civilization]: 129-138.

66. Ronkej S. 2018. [Review]: Accidental death of a professor. On a recent book on Hypatia E.J. Watts, Hypatia. The Life and Legend of an Ancient Philosopher, Oxford, Oxford University Press, 2017, pp. I-XII, 1-205. In: web-site Silvia Ronkej Docenza. Available at: 
http://www.silviaronchey.it/docenza/2/160/Accidental-Death-of-a-Professor-On-a-Recent-Book-onHypatia-E-J-Watts-Hypatia-The-Life-and-Legend-of-an-Ancient-Phi/ (accessed 17 February 2021).

67. Roke D. 1995. Lya Famij d'Ipas'e [The Hypatia Family]. In: Rev'yu des Etyud Greke [Journal of Greek Studies]. 108: 128-149 (in French).

68. Sampson K. 2018. Den h'ente og den glemte Hyupatia [The known and the forgotten Hypatia]. In: Norsk Filosofisk Tidsskrift [Norwegian Philosophical Journal]. Issue. 53, NR. 2-3: 53-65 (in Norwegian).

69. Seeck O. 1966. Geshihte des Untergangs der antiken Vel't [History of the fall of the ancient world]. 6 Volumes. Vol. 6. Darmstadt. Vissenshaft lie Buhgezell'shaft (in German).

70. Tannery P. 1880. L'artikl' de Suida sur Ipas'e [Suidas' article on Hypatia]. In: Anal de Fakulte de Letr de Bordo [Annals of the Faculty of Letters of Bordeaux]. 2: 197-200 (in French).

71. Toland J. 1753. Hypatia: Or, the History of a most beautiful, most vertuous, most learned, and every way accomplish'd Lady; who was torn to Pieces by the Clergy of Alexandria, to gratify the Pride, Emulation, and Cruelty of their Archbishop, commonly but undeservedly stiled St. Cyril. London, 36.

72. Volter F.-M. A. 1860. Ipatie [Hypatia]. In: Dikt'oner filosofik. Uvre komplete de Volter: Nuvej edis'on [Philosophical dictionary. Complete works of Voltaire: New edition]. Vol. 13. Paris: 585-586 (in French).

73. Waithe M.E. 1987. A History of Women Philosophers. Vol. 1: Ancient Women Philosophers, 600 B. C. -500 A. D. Dordrecht, Nijhoff, 229.

74. Watts E.J. 2006. City and School in Late Antique Athens and Alexandria. Berkeley, Los Angeles, London, University of California Press, 288.

75. Watts E.J. 2017. Hypatia. The Life and Legend of an Ancient Philosopher. Oxford, Oxford University Press, 205.

76. Whitfield B.J. 1995. The Beauty of Reasoning: A Reexamination of Hypatia and Alexandria. In: The Mathematics Educator. T. 6 (1): 14-21.

77. Vol'f S. 1879. Hipatia, di Filozofin fon Aleksandrin: Ir Leben, Virken und Lebenzende nah den Kvellenshriften dargestell't [Hypatia, the philosopher of Alexandria: Her life, work and end of life depicted according to the source scriptures.]. Vienna: Hol'der, 41 (in German).

ИНФОРМАЦИЯ ОБ АВТОРЕ

Суслов Федор Александрович, учитель истории МБОУ СОШ № 35, г. Белгород, Россия

\section{INFORMATION ABOUT THE AUTHOR}

Fedor A. Suslov, history teacher secondary school № 35, Belgorod, Russia 